\title{
41 \\ GIANT CELL TUMOR OF THE SACRUM AND CURRENT TREATMENT STRATEGIES
}

\author{
(1) Ali ÖNER, (1) Yunus Emre AKMAN
}

Metin Sabancı Baltalimanı Osteopathic Training and Research Hospital, Clinic of Orthopedics and Traumatology, Istanbul, Turkey

\begin{abstract}
Objective: Giant cell tumor (GCT) is a benign local aggressive tumor seen mostly in the third and fourth decades. Sacrum is the most commonly affected spinal region, followed by thoracic, cervical and lumbar regions. Aim of this study is to evaluate the results of surgical treatment in sacral GCT and review the treatment options of GCT in this uncommon location.

Materials and Methods: Between 2002 and 2018, online hospital database search was conducted for a diagnosis of sacrum and GCT. Patient records were evaluated for recurrence and called for last follow-up.

Results: There were four patients (one male, three female) operated due to sacral GCT, included in the study. Mean follow-up was 49 (25 to 82 ) months. High speed burr, electrocauterization and phenol were used as adjuvant treatment in all cases. Cementing was used in two patients. Conclusion: En bloc resection is the most effective treatment method with the lowest recurrence rate, yet it has the highest morbidity. In addition to intralesional curettage, high speed burr, electrocauterization, phenol and cement as adjuvant therapies can be used in the treatment of GCTs to decrease local recurrence in sacral cases while protecting neural tissues.

Keywords: Giant cell tumor, sacrum, phenol, cement, electrocauterization, high speed burr
\end{abstract}

\section{INTRODUCTION}

Giant cell tumor (GCT) is a progressive, destructive tumor of unknown origin. It is seen mostly in the third to fourth decades with a slightly higher prevalence in females. Progressive pain and swelling are the most frequent presenting symptoms in extremity GCTs; however, spinal GCTs present with back pain, accompanying radiculopathy, and sometimes with rectal, bladder or sexual dysfunction. GCT constitutes approximately $16.2 \%$ of all primary tumors of the spine ${ }^{(1,2)}$. Sacrum is the most commonly affected spinal location, followed by the thoracic, cervical and lumbar mobile spinal regions, and it is the $4^{\text {th }}$ most frequently seen anatomic location after distal femur, proximal tibia, and distal radius. GCT of the sacrum is usually centered in the S1-S2 region, which may involve nerve roots, and extent into ilium through sacroiliac joint.

$\mathrm{GCT}$ is revealed as an eccentric radiolucent expansile mass in the epiphysis of the long bones on X-ray. A faint, narrow zone of transition may accompany. Cortical destruction, periosteal reaction, and bone loss are not uncommon aggressive features. Even though GCT is a benign tumor, lung metastasis may develop occasionally. Therefore, all newly diagnosed patients should obtain chest imaging. Computerized tomography (CT) is the best radiologic entity to visualize the cortical rim, remaining subchondral bone and lack of internal matrix. A soft tissue component with high cellularity and hemosiderin substance that leads to low to intermediate $\mathrm{T} 1$ and low T2 signal on magnetic resonance imaging (MRI) may be present ${ }^{(3,4)}$. Tumor is vascular and therefore, signal enhancement is present on MRI. An elevated level of ATP-dependent proton pumps in the giant cells generates enhanced fluoro deoxy glucose uptake on positron emission tomography ${ }^{(5,6)}$.

Since GCT in sacrum is a rare entity, most information is from GCTs of all skeletal bones, or small case series of sacral GCTs ${ }^{17}$ 12). Although a recurrence rate of $17.2-50 \%$ is present in spinal $\mathrm{GCTs}{ }^{(13)}$, surgery is the mainstay of the treatment. En bloc resection of GCT has the lowest recurrence rate with a better prognosis compared to intralesional surgical procedures ${ }^{(14,15)}$, yet en bloc resection is either extremely difficult or it is associated with increased morbidity and complication rates of approximately $50-100 \%$ due to the adjacent structures of $\mathrm{GCT}^{(16,17)}$. 
turkishspine

The aim of this study is to evaluate the results of surgical treatment in GCT of the sacrum and to review the treatment strategies in this rarely-seen anatomic location.

\section{MATERIALS AND METHODS}

After obtaining local ethics committee approval from Metin Sabancı Baltalimanı Osteopathic Training and Research Hospital, Medical Specialty Board Ethics Committee (date: 23,12.2019, no: 376) a retrospective review of the patients who were operated due to GCT between 2002 and 2018 was performed. Four patients who were operated due to GCT of the sacrum were included in the study.

All patients were evaluated by a multidisciplinary orthopediconcology team before the treatment procedure. Tumor location and extension were described in Table 1 with patient demographics. All patients were operated with a posterior approach only; however, one patient was re-operated with an anterior-posterior combined procedure due to recurrence, and another patient was re-operated due to inadequate tumor removal and cementing. The follow-up was carried out every three months during the first two years, then annually. Control image studies of the pelvis and chest were conducted during follow-up period.

\section{RESULTS}

Four patients [one male, three female, mean age: 35.8 (30 to 44) years] were treated due to GCT of the sacrum. The mean followup was 49 (25 to 82 ) months. Pain was the main symptom in all patients. There were no urinary or fecal incontinence symptoms in any patients pre- and post-operatively. First patient was treated with total excision of S4-Coccyx region. Two patients were treated with intralesional curettage, adjuvant therapy followed by cementation with polymethlymethacrylate (PMMA). The last patient was treated with intralesional curettage and bone grafting in the first surgery, recurrence was detected after 50 months, then the combined approach with a multidisciplinary surgical team was performed for anterior-posterior resection, and posterior lumbar-iliac reconstruction.

\section{DISCUSSION}

GCT is a rare, benign but locally aggressive tumor, which can progress and cause pathologic fractures. Pathologic fracture may be present in up to $30 \%$ of patients ${ }^{(14,15,18)}$. Various treatment options such as surgery, radiotherapy (RT), embolization, cryotherapy, and chemical adjuvants are used for GCT of the spine. Surgical treatment generally includes intralesional curettage, adjuvant therapy as possible and grafting/cementing with or without internal fixation ${ }^{(4,19)}$.

The purpose of the treatment is to remove the tumor and to prevent its recurrence, as spinal structures protected, and neurologic impairment prevented. Although total en bloc resection is the best surgical treatment method, it is not always possible in spinal GCTs because of injury potential to adjacent main neurovascular structures, such as medulla spinalis, aorta, vena cava, ductus thoracicus, and vertebral artery. Blunt dissection is used to protect these important structures, which may lead to excessive bleeding, contamination during removal of tumor cells, and spinal instability may develop secondary to spinal osteotomies for tumor resection. Boriani et al.(14,15), reported good results with en bloc resection to decrease local recurrence compared to other spinal GCT procedures, such as piecemeal resection, RT, and embolization alone. One of our patients, whose lesion was located in S4-S5 region, was treated with en bloc resection, there was no recurrence during the last follow-up (Figure 1).

Intralesional curettage and bone grafting was described previously by Puthoor and lype ${ }^{(20)}$, and Blackley et al. ${ }^{(21)}$ with a recurrence rate of $14 \%$ and $12 \%$, respectively. In our study, intralesional curettage and bone grafting was performed in primary surgery in the patient with recurrence, and the patient was symptom-free in the first 2 years postoperatively, and the patient was lost to follow-up after the $3^{\text {rd }}$ year. Intralesional

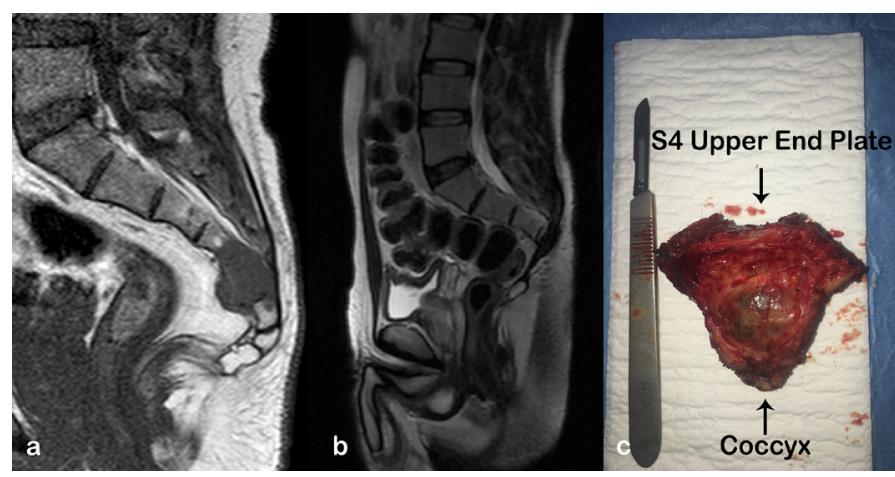

Figure 1. Male patient, 44-year-old. En bloc resection at upper end plate of S4 was performed. a. Preoperative sagittal view of GCT at S4 and S5. b. Postoperative sagittal view. c. Pathology specimen GCT: Giant cell tumor

Table 1. Patient demographics, tumor locations

\begin{tabular}{lllll}
\hline Patient no & Gender & Age (Year) & Follow-up (months) & Tumor Location \\
\hline $\mathbf{1}$ & Male & 44 & 25 & S4 and S5 corpus \\
\hline $\mathbf{2}$ & Female & 32 & 43 & Ala of Right S1 \\
\hline $\mathbf{4}$ & Female & 30 & 46 & Ala of right S1 and posterior ilium \\
\hline
\end{tabular}


curettage + bone grafting alone has some controversies compared to curettage + cementing and also adding adjuvant therapies. In the systematic review of Zuo et al.(22) published in 2013, local recurrence rate was higher in curettage + bone grafting than in curettage + cementing patients. Also, curettage + grafting + adjuvant treatment was found with a higher recurrence rate than curettage + cementing + adjuvant patients in the same systematic review. In the systematic review of Vaishya et al. ${ }^{(23)}$, an overall recurrence rate of $20.4 \%$ in six studies and $42 \%$ in one study were reported. Even though grafting was used in one of our patients, we have been preferring cementing over grafting in GCTs in our clinic, respecting the literature and our clinical experience.

The patient re-applied with pain localized in the sacral region in the postoperative $5^{\text {th }}$ year. A large recurrent mass was detected, biopsy confirmed recurrent GCT, and therefore anteriorposterior partial sacral and iliac resection was performed with iliolumbar reconstruction.

In patients undergoing intralesional procedures, adjuvant therapy modalities such as cryotherapy, burr, cauterization, cementation, and phenol were described to decrease the recurrence rates. In long bones, cryosurgery was introduced in 1964 , which had a recurrence rate less than $10 \%$, but there were some major complications, such as fractures, delayed bone and wound healing, and osteoarthritis(24-26). Because of risks to the neurologic structures, we do not use cryotherapy in spinal cases. Curettage using high-speed burr as an adjuvant therapy in addition to autologous bone grafting and allograft packing was used by Blackley et al. ${ }^{(21)}$, with a recurrence rate of $12 \%$. The combination of high-speed burr with a thermal (cauterization or cryotherapy) or chemical adjuvant modality decreased the recurrence rate ${ }^{(21,26,27)}$. Despite the limited use of high-speed burr in spinal cases, we have been using on the walls of sacrum distant from nerve roots. The use of phenol as an adjuvant therapy has controversies in literature. Phenol has been used as local adjuvant therapy for extremity GCTs, with comparable results with cryotherapy ${ }^{(13,28)}$. In the report of Klenke et al. ${ }^{(29)}$, recurrence was not decreased in patients treated with phenol as an adjuvant therapy to intralesional curettage and bone grafting. We believe that tumor removal with thorough curettage is more important than using phenol alone. However, intralesional curettage, adjuvant therapy and cementing with PMMA have lower recurrence rates than curettage and bone grafting ${ }^{(29,30)}$. We have been using phenol as adjuvant therapy in sacral GCTs, by using a small gauge saturated with phenol. Two patients were treated with curettage, adjuvant therapy (high speed burr, cauterization and phenol application) and cementing and there were no recurrences in these patients (Figure 2). PMMA has a small zone of cytotoxic effect due to exothermic reaction which results in less complications compared to cryotherapy ${ }^{(24,26)}$. In addition, since PMMA is durable in compressive forces, filling the curettage void with
PMMA supports the bone and prevents fractures. In our clinic, after intralesional curettage, we fill the cavity with the contrast medium, and use fluoroscopy to compare the extension of curettage borders with preoperative CT images, which helps total removal of tumor tissue (Figure 3). After adequate removal of tumor tissue, we use blunt tip of osteotomes to protect neural structures from thermal complications of cementing and apply PMMA (Figure 4). Intralesional curettage with high-speed burr, cauterization and phenol application as possible and cementation is the primary choice in GCTs without soft tissue components with intact bone structure in long bones, pelvis and sacrum, yet it may be impossible to perform curettage with high-speed burr and to use of PMMA in other regions of the spine.

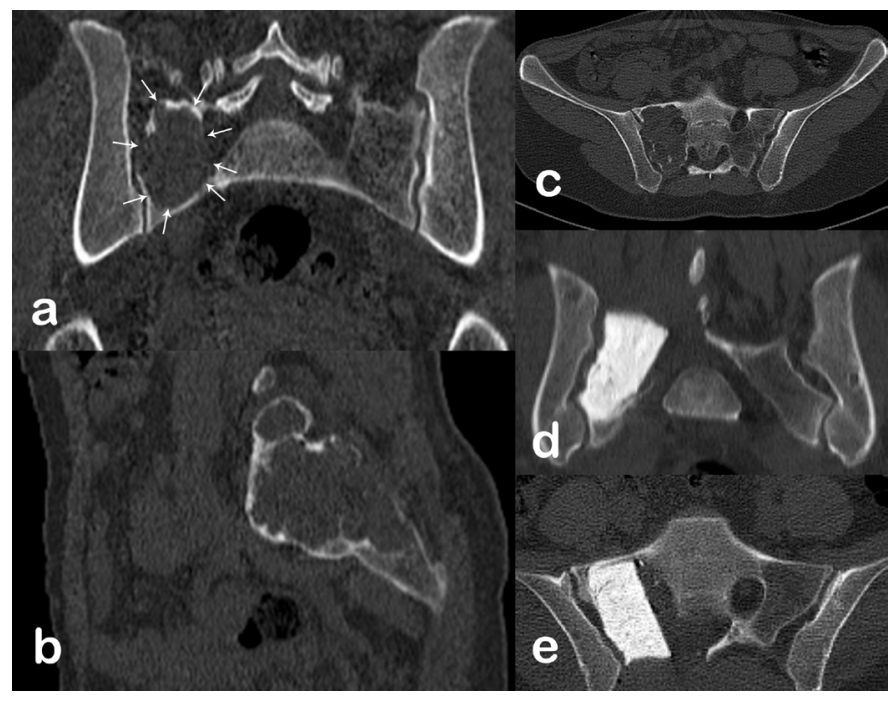

Figure 2. Female, 32-year-old. a. Preoperative axial view, CT of GCT at right S1 \& S2. b. Preoperative sagittal view, CT. c. Preoperative coronal view, CT. d. Cement as adjuvant therapy seen on postoperative axial view. e. Cement is seen on postoperative coronal view

$\mathrm{CT}$ : Computed tomography, GCT: Giant cell tumor

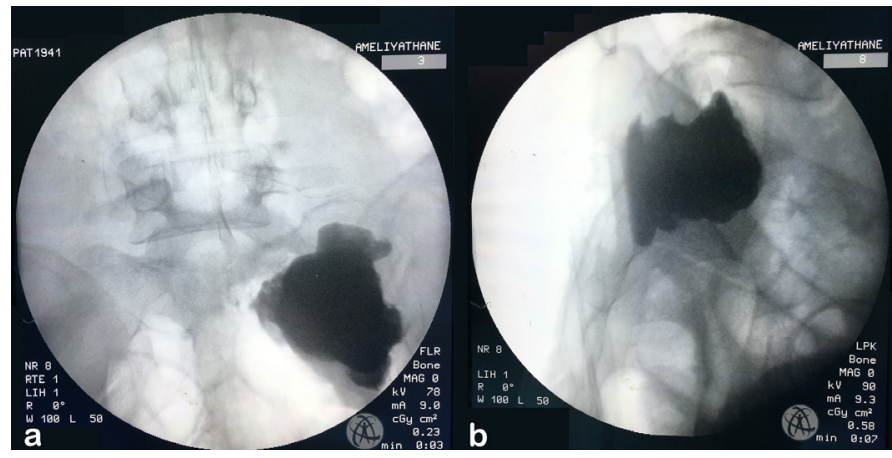

Figure 3. After removal of tumor, void is filled with contrast and fluoroscopy is used to control the borders of curettage borders. If it is insufficient, re-curettage is performed. a. AP view b. Lateral view

AP: Anteroposterior 
turkishspine

Cauterization is used as necrotizing adjuvant therapy in extremities $^{(10)}$, yet we are not aware of any reports in literature for its use in spinal GCTs. Also, high-speed burr is frequently used to remove remaining tumor from the walls in extremities, yet its use is limited in the spine ${ }^{(15)}$. Phenol is used in GCTs of extremities as adjuvant therapy, yet its use is not suggested in spinal cases due to risks to the medulla spinalis and nerve roots $^{(15)}$. Among patients with intralesional curettage in extremity GCTs, phenol as adjuvant therapy has a higher recurrence rate in grafting than cementing patients ${ }^{(30)}$. However, we used high-speed burr, electrocautery, and phenol safely in the present study, and we believe they can be used with neural tissue protective precaution safely, such as using a small sponge saturated with phenol for the application of phenol on the walls (Figure 5).

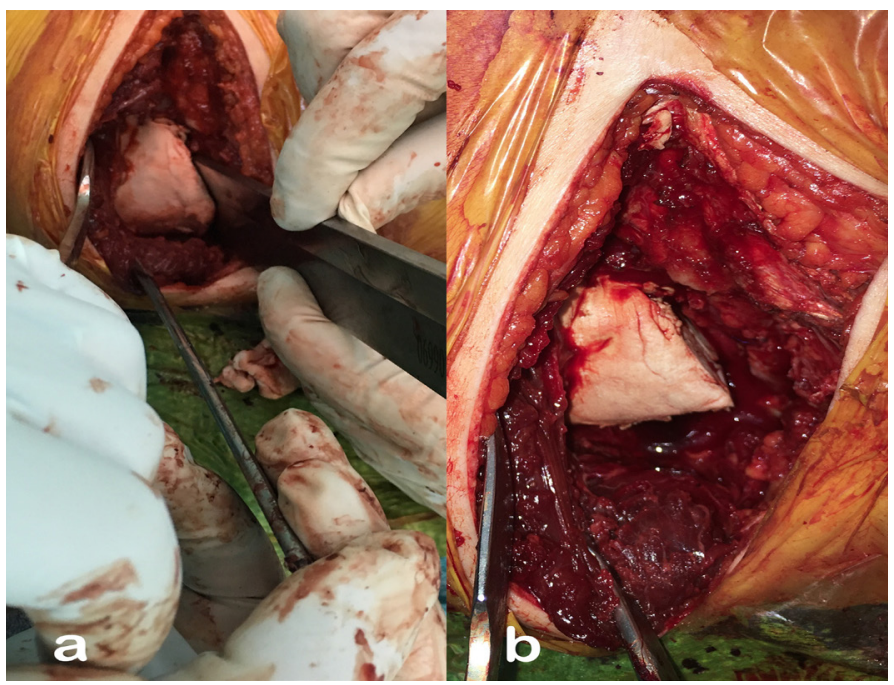

Figure 4. High-viscosity cement can be safely used by using blunt tip of osteotomes to protect neural structures. a. During application and setting cement. b. Posterior view after removal of osteotomes

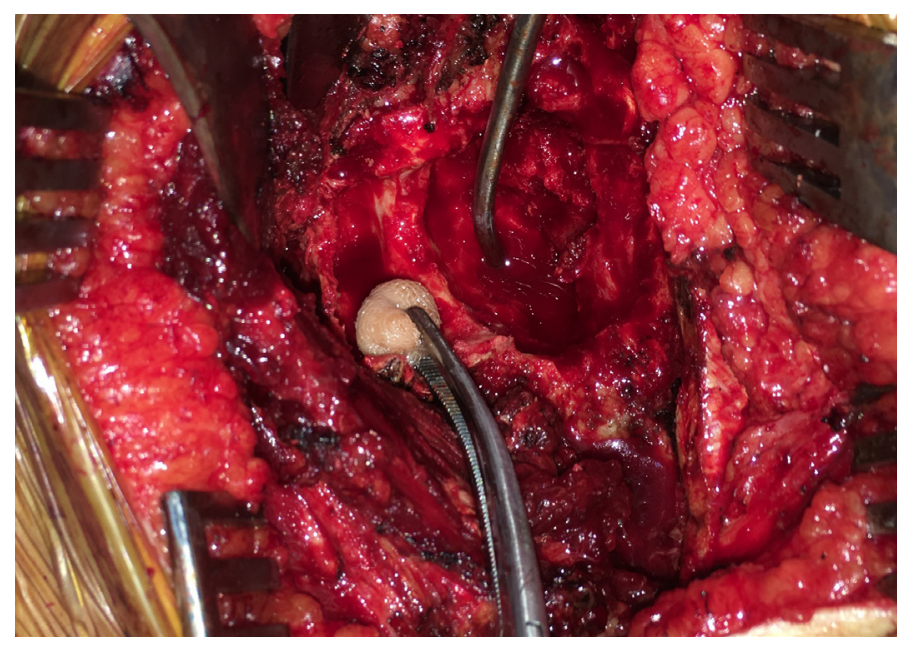

Figure 5. By saturating a small sponge with phenol, walls can be treated with it safely
There was no case treated with preoperative embolization or RT in our series. However, preoperative embolization followed by resection is an option in large $\mathrm{GCTs}^{(7,31,32)}$. RT is suggested to decrease postoperative recurrence in GCT. However, there is still debate on the development of myelopathy and sarcoma secondary to $\mathrm{RT}^{(19,33)}$.

Lung metastasis has been reported in $3 \%$ of the cases $^{(4)}$. However, as high as $15.6 \%$ rate of lung metastasis has also been reported ${ }^{(30)}$. Lung metastasis in GCT usually represents as benign with long survival time and without malignant histologic cases, yet it may become progressive in certain cases, with a mortal course ${ }^{(15,30,34,35)}$. Metastatic spots are usually not painful, and they are either observed or marginally excised via thoracotomy ${ }^{(10,11,33)}$. Chest radiograms should be studied for metastasis evaluation during follow-up. There was no case with lung metastasis in our series. Imatinib (Novartis, East Hanover, NJ, USA) is the choice of drug for the treatment of lung metastasis; however, chemotherapy with Adriamycin and Cisplatin may be preferred ${ }^{(36)}$. Lately, Denosumab, a monoclonal antibody to RANKL, has been approved by the Food and Drug Administration in adjuvant therapy for primary tumor site(8,37-41), and it has also been used in the adjuvant treatment of lung metastasis $^{(42)}$. There was no patient treated with Denosumab in this study population. We had no experience with Denosumab previously, hence it was not used in the patient with recurrence. However, we have been using Denosumab treatment in large GCTs of long bones recently, which has promising results in surgical treatment of the large tumors in our clinical experience, similar to recent literature.

\section{Study Limitations}

The limitations of our study are the retrospective design, small sample size, and the application of different treatment techniques in our series. Since sacral GCTs are rare tumors, it is difficult to design a prospective design in a single center Prospectively randomized designed multi-center studies with larger patients' groups are required.

\section{CONCLUSION}

Careful curettage of all tumor outweighs the adjuvant therapy, and cementing has better local recurrence rates than grafting. Thus, intralesional curettage and filling void with PMMA is the primary option in patients without soft tissue component in sacral GCTs. Patients need to be monitored with radiographs and CT for lesion recurrence and pulmonary metastases. Refractory, recurrent, and particularly aggressive lesions may undergo en bloc excision, yet for the areas that are inaccessible and difficult to treat such as the skull base, and for large lesions with soft tissue component of the spine, pelvis, and sacrum in adults and adolescents, there are limited options. In those patients, embolization, RT, or Denosumab treatment may be 
used as standalone therapy or as adjuvant therapy in addition to surgical treatment.

\section{Ethics}

Ethics Committee Approval: Ethical approval is obtained from Metin Sabancı Baltalimanı Osteopathic Training and Research Hospital, Medical Specialty board Ethics Committee (date: 23.12.2019 no: 376).

Informed Consent: Retrospective study.

\section{Authorship Contributions}

Surgical and Medical Practices: A.Ö., Y.E.A., Concept: A.Ö., Design: A.Ö., Y.E.A., Data Collection or Processing: A.Ö., Analysis or Interpretation: A.Ö., Y.E.A., Literature Search: A.Ö., Writing: A.Ö., Y.E.A.

Conflict of Interest: No conflict of interest was declared by the authors.

Financial Disclosure: The authors declared that this study received no financial support.

\section{REFERENCES}

1. Orguc S, Arkun R. Primary Tumors of the Spine. Semin Musculoskelet Radiol. 2014;18:280-99.

2. Dang L, Liu X, Dang G, Jiang L, Wei F, Yu M, et al. Primary tumors of the spine: a review of clinical features in 438 patients. J Neurooncol. 2015; 121:513-20.

3. Murphey MD, Nomikos GC, Flemming DJ, Gannon FH, Temple HT, Kransdorf MJ. From the archives of AFIP. Imaging of giant cell tumor and giant cell reparative granuloma of bone: radiologic-pathologic correlation. RadioGraphics. 2001;21:1283-309.

4. Parman LM, Murphey MD. Alphabet Soup: Cystic Lesions of Bone. Semin Musculoskelet Radiol. 2000;4:0089-0102.

5. Skubitz KM, Cheng EY, Clohisy DR, Thompson RC, Skubitz APN. Gene expression in giant cell tumors. J Lab Clin Med. 2004;144:193-200.

6. Morgan T, Atkins G], Trivett MK, Johnson SA, Kansara M, Schlicht $\mathrm{SL}$, et al. Molecular profiling of giant cell tumor of bone and the osteoclastic localization of ligand for receptor activator of nuclear factor kappaB. Am J Pathol. 2005;167:117-28.

7. Martin C, McCarthy EF. Giant cell tumor of the sacrum and spine: series of 23 cases and a review of the literature. lowa Orthop J. 2010;30:69-75.

8. Gong LH, Liu WF, Ding Y, Zhang W, Yang YK, Yu F, et al. Clinical, radiologic and pathologic features of giant cell tumor of bone treated with denosumab. Zhonghua Bing Li Xue Za Zhi. 2018;8;47:449-54.

9. Kim SC, Cho W, Chang U-K, Youn SM. Clinical Outcome of Treatment for Patients with Giant Cell Tumor in Spine. J Korean Neurosurg Soc. 2015;58:248-53.

10. Domovitov SV, Chandhanayingyong C, Boland PJ, McKeown DG, Healey JH. Conservative surgery in the treatment of giant cell tumor of the sacrum: 35 years' experience. J Neurosurg Spine. 2016;24:228-40.

11. Jamshidi K, Bagherifard A, Mirzaei A, Bahrabadi M. Giant Cell Tumor of the sacrum: Series of 19 patients and Review of the Literature. Arch Bone Jt Surg. 2017;5:443-50.

12. Hussain S, Makhdoomi R, Khursheed N, Aiman A, Bhat N. Giant Cell Tumor of Sacrum: a Report of Two Cases (Internet). J Turk Spinal Surg. 2015;26:47-50.

13. Dürr HR, Maier M, Jansson V, Baur A, Refior HJ. Phenol as an adjuvant for local control in the treatment of giant cell tumour of the bone. Eur J Surg Oncol. 1999;25:610-8.
14. Campanacci M, Baldini N, Boriani S, Sudanese A. Giant-cell tumor of bone. J Bone Joint Surg Am. 1987;69:106-14.

15. Boriani S, Bandiera S, Casadei R, Boriani L, Donthineni R, Gasbarrini A, et al. Giant cell tumor of the mobile spine: a review of 49 cases. Spine (Phila Pa 1976). 2012;37:E37-45.

16. Turcotte RE, Sim FH, Unni KK. Giant cell tumor of the sacrum. Clin Orthop Relat Res. 1993:215-21.

17. Sar C, Eralp L. Surgical treatment of primary tumors of the sacrum. Arch Orthop Trauma Surg. 2002;122:148-55.

18. Enneking WF, Spanier SS, Goodman MA. A system for the surgical staging of musculoskeletal sarcoma. 1980. Clin Orthop Relat Res. 2003:4-18.

19. Miszczyk L, Wydma ski J, Spindel J. Efficacy of radiotherapy for giant cell tumor of bone: given either postoperatively or as sole treatment. Int | Radiat Oncol Biol Phys. 2001;49:1239-42.

20. Puthoor D, lype W. Giant cell tumor: Curettage and bone grafting Indian J Orthop. 2007;41:121-23.

21. Blackley HR, Wunder JS, Davis AM, White LM, Kandel R, Bell RS Treatment of giant-cell tumors of long bones with curettage and bone-grafting. J Bone Joint Surg Am. 1999;81:811-20.

22. Zuo D, Zheng L, Sun W, Fu D, Hua Y, Cai Z. Contemporary adjuvant polymethyl methacrylate cementation optimally limits recurrence in primary giant cell tumor of bone patients compared to bone grafting: a systematic review and meta-analysis. World I Surg Oncol. 2013;16;11:156.

23. Vaishya R, Pokhrel A, Agarwal AK, Vijay V. Current status of bone cementing and bone grafting for giant cell tumour of bone: $A$ systemic review (Internet). Ann R Coll Surg Engl. 2019;101:79-85.

24. Marcove RC, Weis LD, Vaghaiwalla MR, Pearson R, Huvos AG Cryosurgery in the treatment of giant cell tumors of bone. A report of 52 consecutive cases. Cancer. 1978;41:957-69.

25. Jacobs PA, Clemency RE. The closed cryosurgical treatment of giant cell tumor. Clin Orthop Relat Res. 1985:149-58.

26. Malawer MM, Bickels I, Meller I, Buch RG, Henshaw RM, Kollender Y. Cryosurgery in the treatment of giant cell tumor: A long term followup study. Clin Orthop Relat Res. 1999:176-88.

27. O'Donnell RJ, Springfield DS, Motwani HK, Ready JE, Gebhardt MC, Mankin HJ. Recurrence of giant-cell tumors of the long bones after curettage and packing with cement. J Bone Joint Surg Am. 1994;76:1827-33.

28. Capanna R, Sudanese A, Baldini N, Campanacci M. Phenol as an adjuvant in the control of local recurrence of benign neoplasms of bone treated by curettage. Ital J Orthop Traumatol. 1985;11:381-8.

29. Klenke FM, Wenger DE, Inwards CY, Rose PS, Sim FH. Giant cell tumor of bone: risk factors for recurrence. Clin Orthop Relat Res. 2011;469:591-9.

30. Klenke FM, Wenger DE, Inwards CY, Rose PS, Sim FH. Recurrent giant cell tumor of long bones: analysis of surgical management. Clin Orthop Relat Res. 2011;469:1181-7.

31. He S, Xu W, Sun Z, Liu W, Liu Y, Wei H, et al. Selective Arteria Embolization for the Treatment of Sacral and Pelvic Giant Cell Tumor: A Systematic Review. Orthop Surg. 2017;9:139-44.

32. Wu Z, Yang X, Xiao J, Feng D, Huang Q, Zheng W, et al. Aneurysmal bone cyst secondary to giant cell tumor of the mobile spine: a report of 11 cases. Spine (Phila Pa 1976). 2011;36:E1385-90.

33. Feigenberg SJ, Marcus Jr RB, Zlotecki RA, Scarborough MT, Berrey BH, Enneking WF. Radiation therapy for giant cell tumors of bone. Clin Orthop Relat Res. 2003;411:207-16.

34. Yin H, Cheng M, Li B, Li B, Wang P, Meng T, et al. Treatment and outcome of malignant giant cell tumor in the spine. J Neurooncol 2015;124(2):275-81.

35. van der Heijden $L$, van de Sande MAJ, van der Geest ICM, Schreuder HWB, van Royen BJ, Jutte PC, et al. Giant cell tumors of the sacrum-a nationwide study on midterm results in 26 patients after intralesional excision. Eur Spine J. 2014;23(9):1949-62. 
turkishspine

36. William Makis, Z. Alabed, Ayoub Nahal, Javier A. Novales-Diaz, Marc Hickeson Giant Cell Tumor Pulmonary Metastases Mimic Primary Malignant Pulmonary Nodules on 18F-FDG PET/CT. Nucl Med Mol Imaging. 2012;46:134-37.

37. Lin P, Lin N, Teng W, Wang SD, Pan WB, Huang $X$, et al. Recurrence of Giant Cell Tumor of the Spine after Resection: A Report of 10 Cases. Orthop Surg. 2018;10:107-14.

38. de Carvalho Cavalcante RA, Silva Marques RA, Santos VG dos, Sabino E, Fraga AC, Zaccariotti VA, et al. Spondylectomy for Giant Cell Tumor After Denosumab Therapy. Spine (Phila Pa 1976). 2016;41:E178-82.

39. Inoue $G$, Imura T, Miyagi M, Saito W, Tazawa R, Nakazawa T, et al. Total en bloc spondylectomy of the eleventh thoracic vertebra following denosumab therapy for the treatment of a giant cell tumor. Oncol Lett. 2017; 14:4005-10.

40. Fraile NM, Toloi D, Kurimori CO, Matutino AR, Codima A, Camargo $V P$, et al. Successful Intravascular Correction of Intratumoral Pseudoaneurysm by Erosion of the Aorta in a Patient with Thoracic Giant Cell Tumor of Bone Responding to Denosumab. Case Rep Oncol Med. 2015:626741.

41. Kajiwara D, Kamoda $H$, Yonemoto $T$, Iwata $S$, Ishii T, Tsukanishi $T$, et al. Denosumab for Treatment of a Recurrent Cervical Giant-Cell Tumor. Asian Spine J. 2016;10:553-57.

42. Watanabe $Y$, Kaya $M$, Sasaki $M$, Emori $M$, Murahashi $Y$, Mizushima $E$ et al. Experience using denosumab for lung metastases of giant cell tumor of bone. Eur Orthop Traumatol. 2015;6:239-41. 